\title{
Online Learning Experience and Challenges of Undergraduate Students During COVID-19
}

\author{
Afaaf Rubal \\ Farhat Abdullah ${ }^{2}$ \\ Khalid Ahmed ${ }^{3}$ \\ Ayesha Basharat ${ }^{4}$
}

${ }^{1}$ University of Central Punjab - Lahore, Pakistan

${ }^{2}$ University of Central Punjab - Lahore, Pakistan

${ }^{3}$ University of Central Punjab - Lahore, Pakistan

${ }^{4}$ University of Central Punjab - Lahore, Pakistan

\begin{abstract}
The paper presents a comprehensive view of students' viewpoints on online learning and academic, psychological, domestic, and social problems. The study analyzed different aspects of online learning and their effects on students' lives. This research aimed to analyze the concerns of undergraduate students of the University of Central Punjab. Due to the closure of physical classes and institutes, the data collection for this study was done online through a survey questionnaire structured on google forms. A primary source of data collection was used and a sample of 100 students from different departments of the University of Central Punjab was approached. Responses to the survey questionnaire served to represent students' stance on online learning. A majority of respondents showed satisfaction over online learning and grading system. Similarly, most of the respondents had a neutral perspective on Microsoft Teams as a learning platform. Assignment submission and attempting quizzes was not a very difficult task for the university students. Poor internet connection was a major issue along with a lack of motivation for students in online classes. The study addressed major issues faced by students during online classes and learning feedback on the shifted system of online classes due to COVID-19.
\end{abstract}

Keywords: Online Learning, Respondents, COVID-19, Google Forms, Feedback

Author'sE-mail:farhat.abdullah@ucp.edu.pk 


\section{Introduction}

Covid-19 has divulged as an epidemic that has constituted a contemporaneous threat or warning to the whole of humankind. This epidemic has strongly enforced worldwide closure of various exertions or activities, as well as an educational enterprise, and this has emerged as an enormous response to the crisis's emigration of universities with distance learning operating as the academic platform. As we all know, Covid-19 has come across in Wuhan's seafood market in the end month of the year 2019 . Online learning is frequently used conversely with overlapping and definite terms such as blended learning, distance, and e-learning. In the past three years, online learning has just internationally become a considerable and important part of educational learning (Singh \& Thurman, 2019). Moreover, online learning is the use of several other dominant technologies and the internet to originate material only for academic grounds, administration of the program, and educational delivery (Fry, 2001). The whole world is attempting to evade the gap and lessen the loss of students produced by the ongoing epidemic. Nevertheless, the consequences of online learning are not every time a blessing or favour to the student's community.

With contemplation to the reality, the current study is an endeavour to demonstrate the challenges and experiences faced by students of undergraduate during this Covid-19 epidemic. As we know, COVID-19 disease was identified in Pakistan in March 2019. About 150 countries worldwide have introduced e-learning platforms as a solution to continue the education process during the pandemic. Online learning has given ease to numerous matters such as time, recorded lectures, and as well as personal space. But at the same time, students faced many challenges and have experienced a lot in these online learning. If we talk about challenges then many students experienced technical problems such as taking classes on teams, difficulty in logging in or turning in assignments, a complication in joining the class, also getting grades during online learning is quite challenging for some students moreover, students encountered many domestic issues during this whole learning experience of online education. So, this whole online learning process was demanding and 
complicated for learners, as well as they experienced much in online education. Online education can be a provocation or challenge for both students as well as facilitators (Jaques\& Salam, 2007).

Some major challenges which students went through in online learning include technical problems, time management, distractions, staying encouraged, understanding course prospects, adjusting to uncommon technology, inadequacy in-person communication or interaction, and unpredictability about the future. Moreover, this study will also demonstrate what students like and don't like about this online learning, whether learners choose it or not, and how much students were pleased with the facilities during online education. The survey targeted 100 participants and we have got 100 responses. $46 \%$ of them were male participants and 54\% of them were female. Candidates belong to several departments and semesters.

\section{Research Objectives}

I. To investigate the equivalent change in students learning and grades in shifted teaching practice.

II. To investigate student's digital literacy rate before and post online education in COVID 19.

III. To analyze the circumstances of a pandemic on students to explore their results.

\section{Research Questions}

The research work aims to answer the following questions:

I. What difference E-learning has induced in student's education and what change has been noticing in the grading criteria in switching circumstances of online courses?

II. How digital literacy has helped students in learning?

III. How pandemic has affected the everyday life of higher education students?

\section{Literature Review}

With the outbreak of the pandemic, the absolute systems were changed and institutions and industries were shut down for a long period (Urdan\&weggen, 2000). The Sloan Consortium reports that the business of life started to resume partially. Educational institutes resumed their classes on virtual grounds. This was done through various online platforms 
as Microsoft teams, zoom and dashboard. COV-ID19 has affected the entire world. Pupils, teachers, businessmen, employers and labourers all have faced difficulties in different ways. In this research, the researcher discussed problems that teachers and students have faced. This partial resume of curricular activities brought several problems for faculty as well as students in Pakistan (Urdan\&weggen, $2000)$. Lack of resources and development is a major problem faced by Pakistan being a developing country (Rosenberg, 2001). Faculty members were equally unprepared for this emergency and this type of virtual classroom. Teachers were given basic workshops for this new system of teaching during pandemic situations but there remained a lot of problems and distress among students and teachers for this new system of online teaching and learning (OwusuFordjour et al. p15]. Students, on the other hand, were facing many problems regarding, connectivity, technical incompetence and household distractions. The whole shift in the system of education from physical to online classes was a new experience for teachers as well as students' issues (Aleksander Aristovnik *, 2020). And besides all technical and domestic issues, the distress of the pandemic situation and the stress of lockdown made things worse at both ends.

The expeditious growth in the usage of assimilating advancement, especially the use of network-based communication or automation has provided educationists much higher convenience to interrogate the most convenient learning conditions for their student's teaching and learning style (Akkoyunlu, B., \&Soylu, M. Y. 2008). The motive of the present study was to scrutinize the students' views and learning style on blended teaching, defining blending learning as "to combine or blend modes of Web-based automation, for example, collaborative learning, self-paced instructions, livevirtual classroom and streaming audio, text and video (Driscoll,2002). The research was conducted at Hacettepe University, with thirty-four students. The two instruments were the questioner planned to recognize students' perspective on Kolb's learning and blended learning Style Inventory. Subsidiary data were assembled from attainment scores of learners and information exemplifies learner's participation in E-learning environment (Akkoyunlu, \&Soylu, M. Y. 2008). E-learning is a usual or 
ordinary method since it is accomplished to present the contented of the course in an extensive period of setup compared to other procedures or practice and classroom environment; it authorizes teaching for seven days, twenty-four hours; it extends an additional number of students or learners; it certifies a teaching environment which is individualistic of place and time (Dziuban, Hartman, \&Moskal, 2004; Osguthorpe\& Graham, 2003) especially for grown-up learners. The use of web environment judgment and face to face conditions depends upon the learning styles. The face-to-face characteristic of the procedure has the highest mean score when the students' evaluation is taken for deliberation. The inclusive findings intimate no consequential differences between student's accomplishment levels as stated in their learning pattern and techniques (SoyluAkkoyunlu, M. Y.2008).

This objective of the research was based upon seven factors, telling the standard or definitive of online learning during the pandemic, which includes administrative, learners, instructor and technical support which are the variables influencing e-learners (Elumalai, K. Sankar, J. P., R, K., John,
Menon, N., AlqahtaniAbumelha. M. A. 2020). The Coronavirus has greatly influenced the educational system, introducing e-learning. Online learning and access to the portals are called elearning. The findings divulged that there is a constructive connection amongst the standard of e-learning as well as the set of variants in the higher learning section, and during the pandemic of Covid-19 there is a consequential difference in the student's perception between levels, of course, gender-specific also the standard of online learning in the educational area (Elumalai, K, Sankar, J. P., R, K., John, Menon, N 2020). Administrative assist becomes a crucial factor in executing certain inventive online learning methods in universities (Barefield\& Meyer, 2010).

We all know that covid-19 has affected the entire world. Pupils, teachers, businessmen, employers and labourers all have faced difficulties in different ways. In this research, the researcher discussed problems that teachers and students have faced. Students had never experienced elearning before, the same is the case with teachers. It was difficult for both to take online classes. Many trials and errors occurred. Some students were 
satisfied but the majority were unhappy. Some of the difficulties faced by people were environmental issues, some educational content which required physical class environment, lack of technical knowledge and also major internet connection problems. Some teachers who were familiar with online classes could easily make it. As it was a sudden shift to online classes so, teachers were unprepared. Many had environmental problems. The environment was not suitable for online classes. Despite facing all these real problems in online classes, the world health organization declared a pandemic to secure our country's assets. Children and students are assets of every country and for their health, a lockdown was essential. If we contrast online and physical classes then physical classes are better than online classes because teachers use different methods to teach students, teachers need immediate feedback so that they could evaluate easily the performance of students. The student's and teacher's environment was not suitable for online classes. Many had environmental problems. The environment was not suitable for online classes. Noisy background, internet problems, electricity problems, many difficulties were faced by teachers as well as students. Pandemic has affected every country and city whether it's Europe, America or any other. In many studies before COVID-19, the possibility of online classes has been examined as a part of future education. So, a change in the curriculum of online classes was compulsory. If we contrast online and physical classes then physical classes are better than online classes because teachers use different methods to teach students, teachers need immediate feedback so that they could evaluate easily the performance of students. Not every subject is easy to like, math etc. Students must make an effort to actively participate in online physical education classes and record the process. Everything has an advantage and disadvantage. So as the online and physical classes. Online classes are not time taking whereas physical classes are (Hyun-ChulJeong\& Wi-Young So, 2020). In online classes, you finish your class in about one-third of the time than it takes you on campus. Whereas oncampus classes take time. Online classes give you ease at many things like time, recording lectures as well as personal space. But at the same time, practical learning is only possible in physical classes. For Example, all the science practical's, art classes etc. are not possible in online classes. 
By 31 July 2020, COVID-19 had spread across $217+$ countries and territories, with almost 17.1 million confirmed cases and 668,073 deaths (Aleksander Aristovnik *, 2020). Recent research conducted by researchers of Slovenia in October 2020 analyzed the global effect of a pandemic on students of higher education from various perspectives. Their study proposed that this shift from onsite to online lectures was marked by high levels of depression and anxiety of higher education students relating to their career, social and domestic issues as well as psychological and institutional issues (Aleksander Aristovnik *, 2020). Specifically, students working along with higher studies and financially unstable students faced hardships more as compared to students with better resources. The study analyzed in-depth the response of students on demographic and geographic elements including comparative learning outcomes and online grading and assignments (Volery, 2000). The study also included responses of students on social, psychological and emotional experiences (Aleksander Aristovnik *, 2020). Modes of teaching and evaluation as well as expectations of students and their performances were recorded. Administrative and teaching criteria were analyzed and their respective outcomes were searched to observe a shift of teaching and learning patterns in onsite and online pedagogical approaches (Johnson \& Berge, 2012). Besides recording the positive and appreciative approach of developed and urban students, the study also kept in view the responses and feedback of rural and remote area resident higher education students (Chang, et.al 2014, p.3). The study concluded its responses in an overall condition of destressing and anxiety in students of higher education (BussakornCheawjindakarn, 2017). Allen and Seaman (2014) stated the rate of satisfaction was greater in developed and relatively equipped areas whereas rural and remote areas show a sharp decline in educational progress and motivation in this epidemic situation.

\section{Methodology}

\section{Population and Sampling}

The target population was UCP undergraduate students. A sample of 100 students was selected randomly and data was collected from that sample. The respondents were both boys and girls. The sample included students of the Faculty of Arts and 
Social Sciences, UCP Business School, School of Accounting and Finance, School of Media and Communication Studies, and UCP Law School. Responses included 46\% responses from Faculty of Arts and Social Sciences, 20\% responses from students of UCP Business School, 6\% participants from Media and Communication Studies, 4\%respondents belonged to School of Accounting and Finance and 24\%responses from UCP Law School students. So, the sample selected randomly was highly representative of the population. Moreover, the participants of the survey were students of different semesters from BS Degree. All the respondents have gone through the online learning environment on Microsoft Teams, so the population and sample were the right respondents for our research.

\section{Research Tool}

For data collection, a mixed type of questionnaire was adapted. The adapted questionnaire consisted of 15 items. Demographics include questions of gender, department, and semester of the respondent. The second section of the survey questionnaire was about online academic experiences that included Likert scale questions. This section included 15 questions about student's satisfaction and viewpoint about the effectiveness of online learning as well as class interaction and response rate of students in online classes. The section serves to know the student's aspects of satisfaction with online grading and attempting online assignments and quizzes. The next section included some questions about student's online literacy and software issues faced by students during online classes on Microsoft Teams. This section included Likert Scale questions on experiences of students during online classes like joining meetings and turning in assignments and quizzes. After this section, domestic and social hindrances for students in learning online were discussed. The psychological concerns of this shift of learning system from on-campus classes to online learning environment were also analyzed through Likert Scale questions and a short question. The survey questionnaire was developed on Google Forms and circulated to respondents online due to physical classes and the closure of the university. The survey questionnaire was adapted with the ideological adaption from (Aristovnik, 2020). 


\section{Data Collection}

Data collection for this research work was done online due to lock down and shifted online learning environment. The survey questionnaire was developed online on Google Forms and the questionnaire was circulated to sample respondents through WhatsApp and email. The survey was circulated on $8^{\text {th }}$ January; 2021 and remained open for responses till $11^{\text {th }}$ January; 2021. After receiving 100 responses, the survey was closed and data were analyzed and discussed.

\section{Data Representation}

The data collected via google forms in the form of a mixed type adapted survey questionnaire gave an insight into student's perspectives of online education. The results achieved from the survey are given below:

Section 1: Demographics:

Demographics of data collected through survey questionnaire show that the sample of 100 students from the University of Central Punjab, 54\% of whom were female and $46 \%$ male participants. Data shows that the sample had students from different semesters and at all levels, students have different experiences, so the sample was highly representative. Data shows that the sample consisted of 5\% students of the first and second semester, $10 \%$ students of third and fourth semester, $13 \%$ participants were enrolled in their fifth or sixth semester whereas a majority of participants were mature students of seventh and eighth semester of undergraduate-level study. Moreover, the sample for data collection included students of different departments. For example; the Faculty of Arts and Social Sciences (FASS), UCP Business School, School of Accounting and Finance, School of Media and Communication Studies, and UCP Law School. The demographics data collected from the survey is given in the following table and pie charts: 
Demographics: Gender of Respondents.

Gender

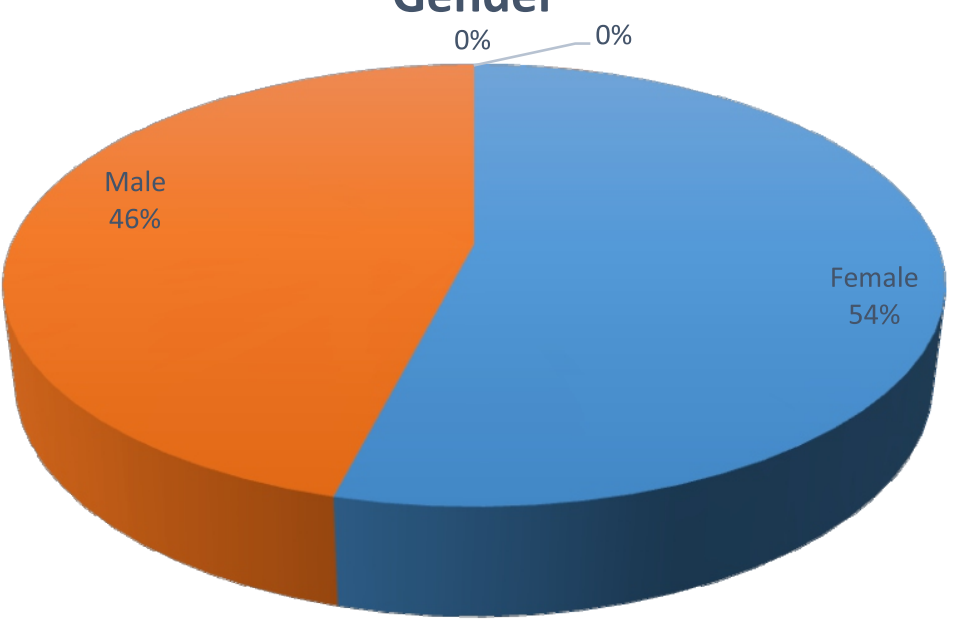

Section 1: Demographics. Graph 1.1: Gender

Demographics: Semester of Respondents

Semester

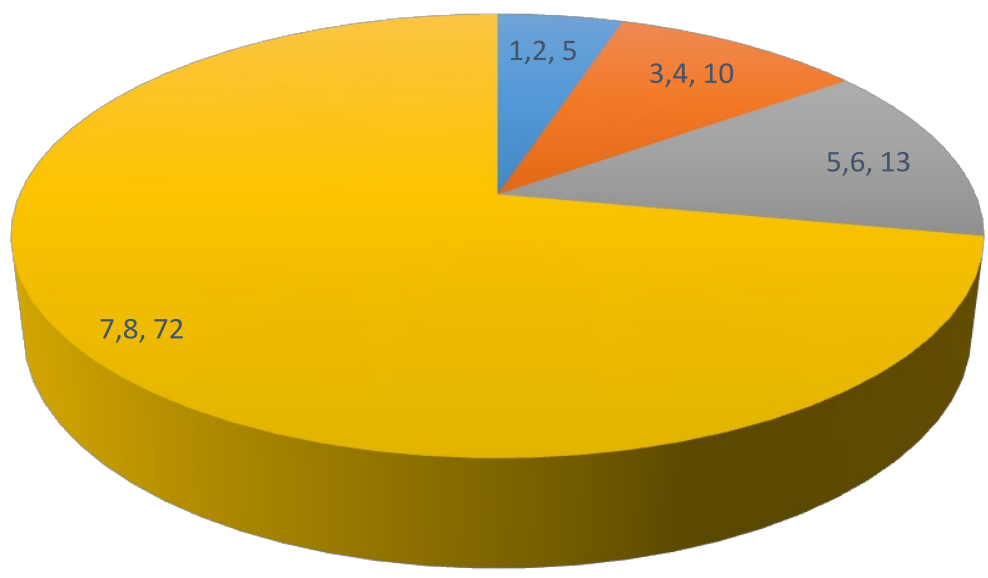

Section 1: Demographics. Graph 1.2: Semester

Section 2: Academic Experiences 
Demographics: Department of Respondents.

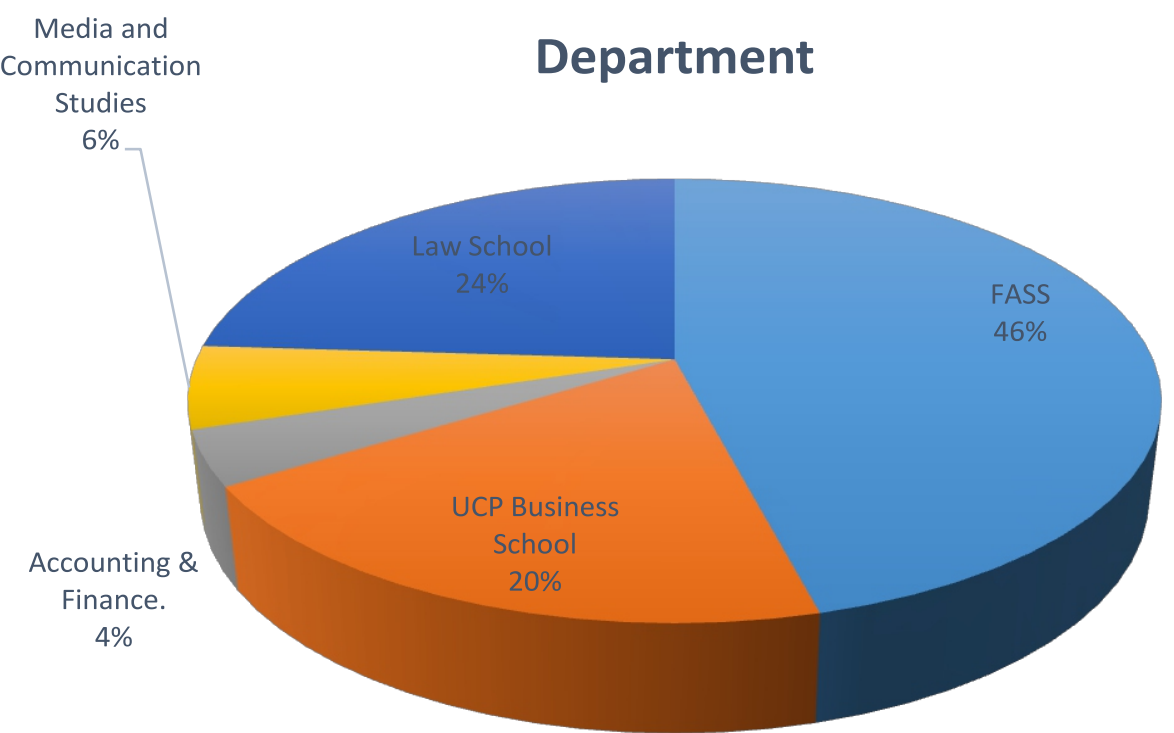

Section 1: Demographics

Graph 1.3: Departmentof Respondents' Effectiveness of e-learning.

\section{Effectiveness of e learning}

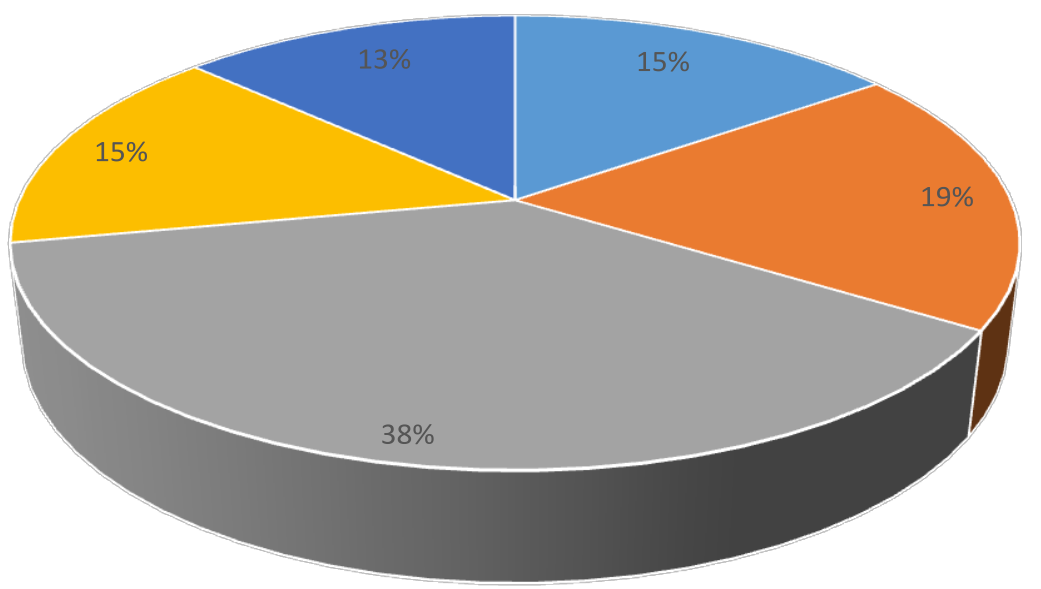

Section 2: Academic Experiences

Graph 2.1: Effectiveness of E-Learning. 
Academic Experiences: Satisfaction with Online Learning.

\section{Satisfaction with Online learning}

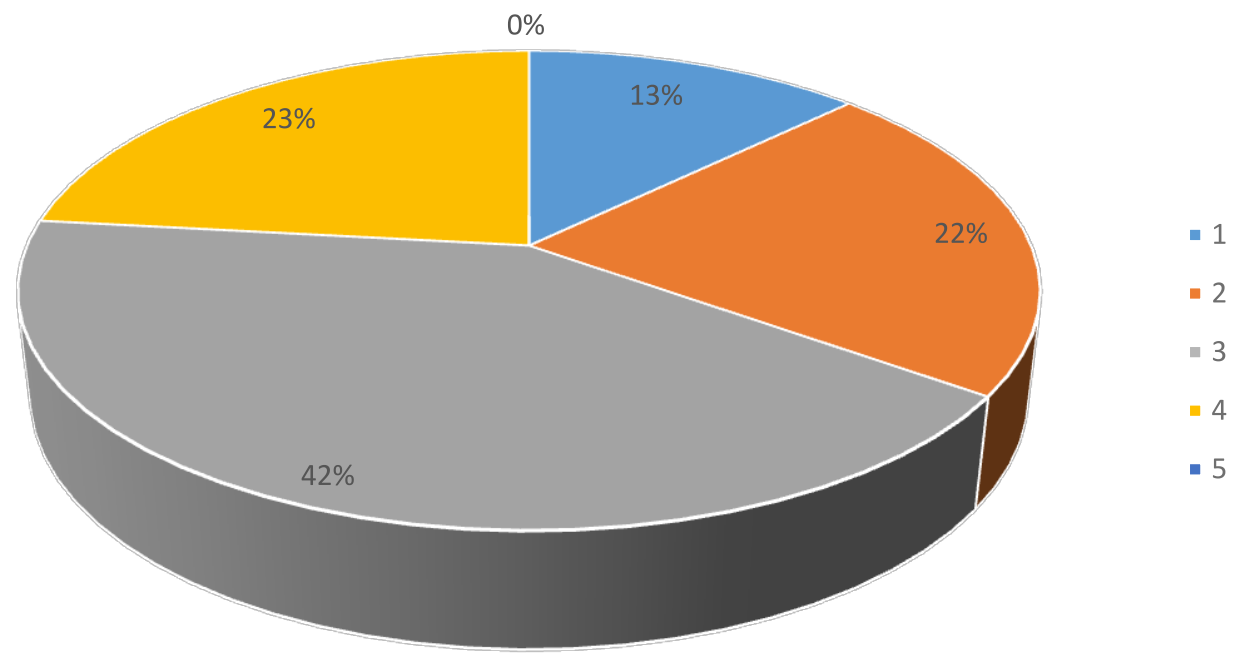

Section 2: Academic Experiences

Graph 2.2: Satisfaction of Students with E-Learning.

In this section, the academic experiences of undergraduate students of UCP students during online learning are collected through Likert Scale questions. Student's perspectives on different aspects of learning and academia in online classes are gathered.

*KEY

$1=$ strongly satisfied

$5=$ strongly dissatisfied

Student's perspective on effective e-learning in the light of results of the survey (graph 2.1; table 2/ annexes) says that $34 \%$ of students were strongly satisfied with the effectiveness of online classes, whereas 38\% of students had a neutral opinion on the stance. The results of the survey responses show that $28 \%$ of students were strongly dissatisfied with this online learning

About online learning (graph 2.2; table $2 /$ annexes), $30 \%$ of students were very much satisfied with online learning and their comprehension in online classes, $36 \%$ of students had neutral feedback whereas $34 \%$ of students showed dissatisfaction over online learning. 
Academic Experiences: Student's Class Response Rate.

\section{Students' Class Response Rate}

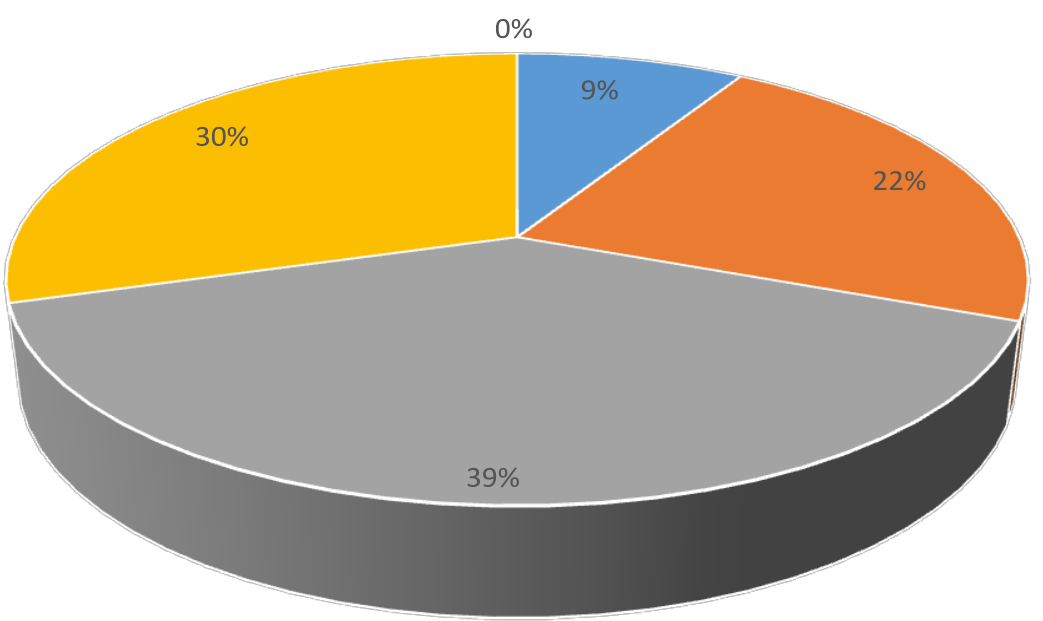

Section 2: Academic Experiences.

Graph 2.3: Students' Class Response Rate.

Academic Experiences: Satisfaction with Online Learning.

\section{Satisfaction with Online Grading}

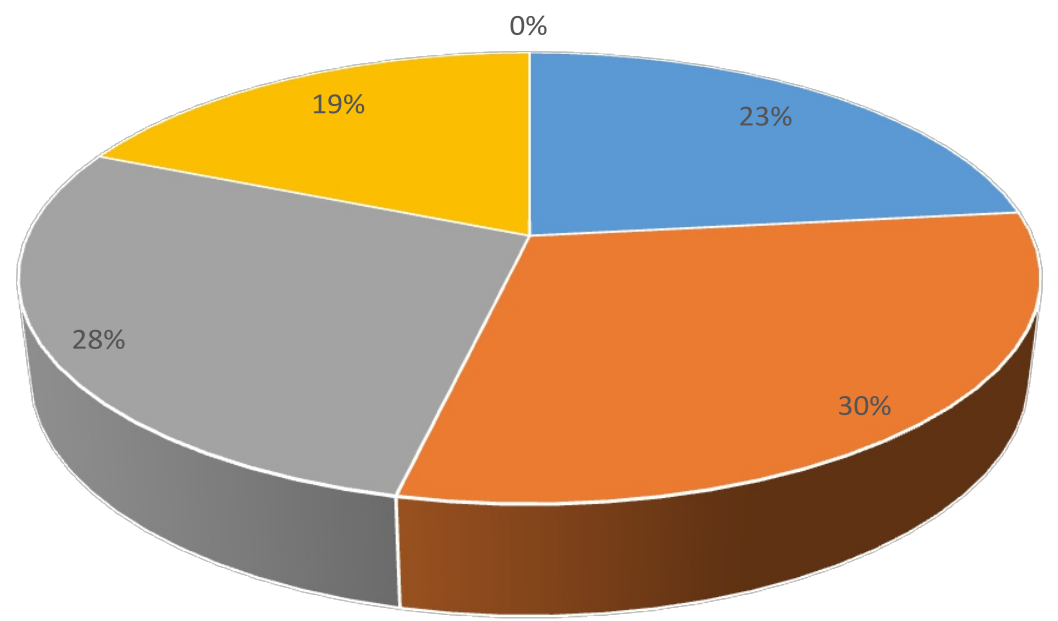

Section 2: Academic Experiences.

Graph 2.4: Students' Satisfaction with Online Grading 
About academics, when student's perspective about student's class participation in discussions and activities was inquired (as illustrated in graph 2.3; table 2/ annexes), $32 \%$ of students said that the rate was not much affected, whereas $25 \%$ students presented their opinion as a positive change in class response rate in online classes. On the other side, $43 \%$ of participants agreed on a decline in the class response rate of students in online classes.
About academics, when student's perspective about student's class participation in discussions and activities was inquired (as illustrated in graph 2.3; table 2/ annexes), $32 \%$ of students said that the rate was not much affected, whereas $25 \%$ students presented their opinion as a positive change in class response rate in online classes. On the other side, $43 \%$ of participants agreed on a decline in the class response rate of students in online classes.

Academic Experiences: Student's Class Response Rate.

\section{Students' Class Response Rate}

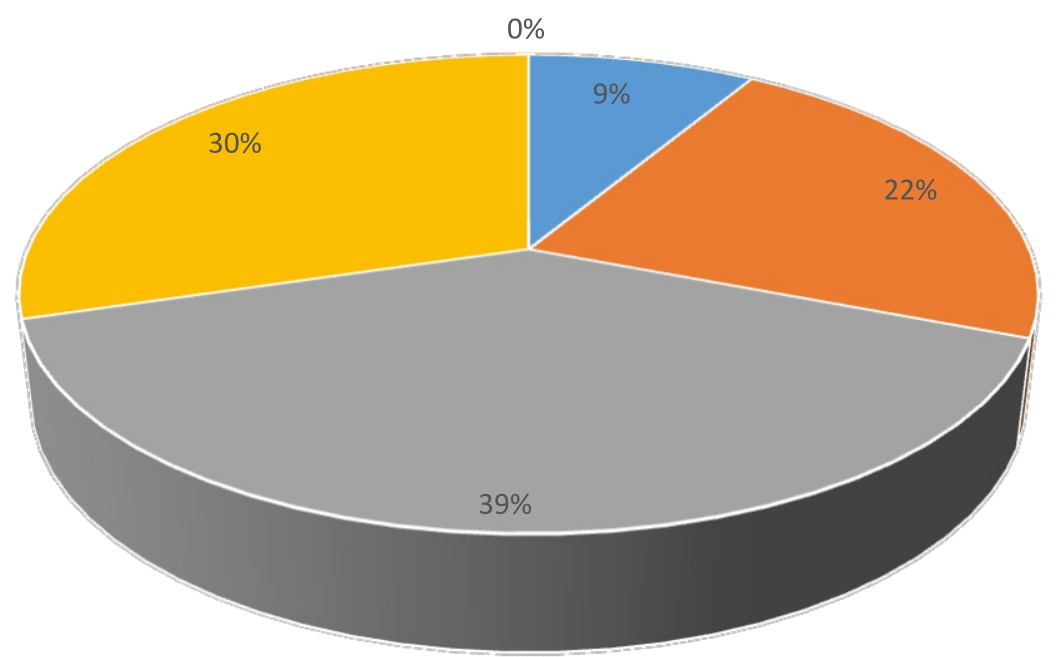

Section 2: Academic Experiences.

Graph 2.3: Students' Class Response Rate. 
Academic Experiences: Satisfaction with Online Learning.

\section{Satisfaction with Online Grading}

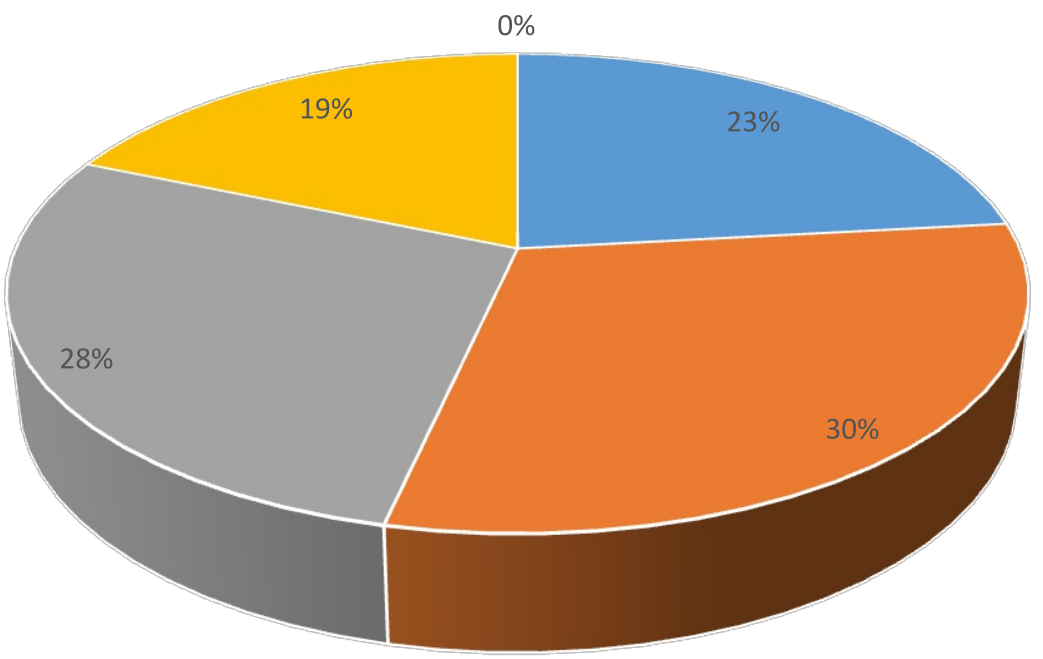

Section 2: Academic Experiences.

Graph 2.4: Students' Satisfaction with Online Grading

The survey results show (as represented in graph 2.4: table 2/ annexes) respondents' views on the grading system in online classes and the marking criteria of teachers. The results show that $46 \%$ of students are very satisfied with online grades and $24 \%$ of students see no drastic change in their grades during online classes as compared to physical classes. However, $30 \%$ of students show their dissatisfaction with the online grading system. 
Academic Experiences: Experience of Online Assignments and Quizzes.

\section{Experience of Online Quizzes \& Assignments.}

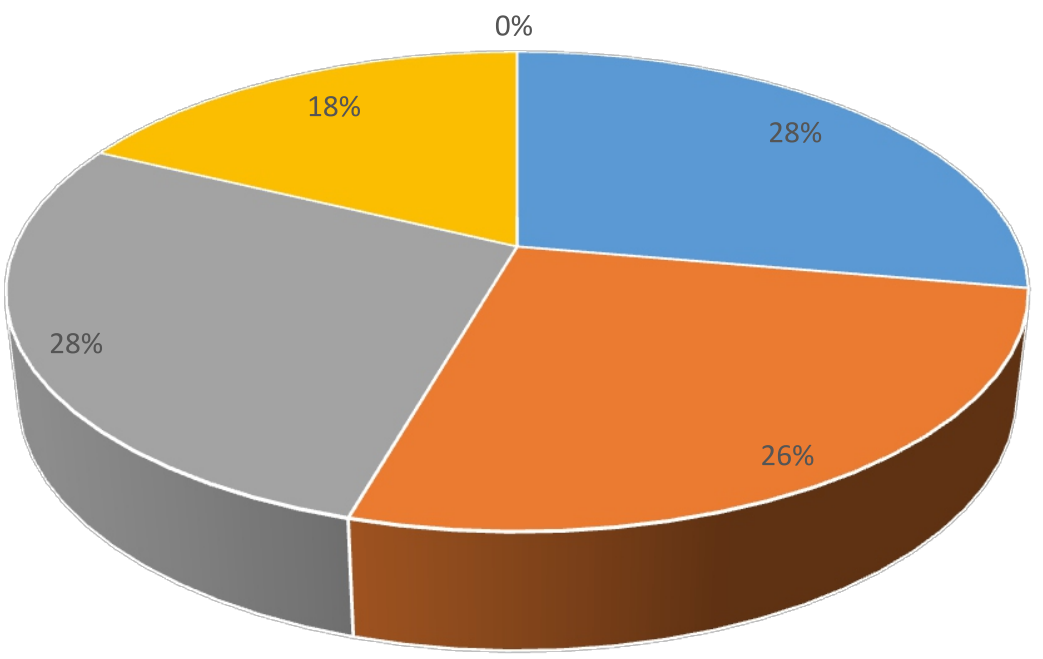

Section 2: Academic Experiences.

Graph 2.5: Experience of Online Quizzes and Assignments.

Section 3: Software and Online Literacy of Students:

In this section, questions were organized to study student's online literacy and software-related technical competence that were helpful in online classes. To $\log$ in to Microsoft Teams and working for projects and activities online, required a great deal of knowledge of Microsoft Edge, Microsoft PowerPoint, Google Forms, Google Spreadsheets, and many other related apps. This section had questions like respondent's experience of logging in to Microsoft Teams, Microsoft Outlook turning in assignments and quizzes and sharing the screen, joining meetings, etc. 
Software and Online Literacy: Microsoft Teams as Online Learning Platform.

\section{Microsoft Teams as Learning Platform}

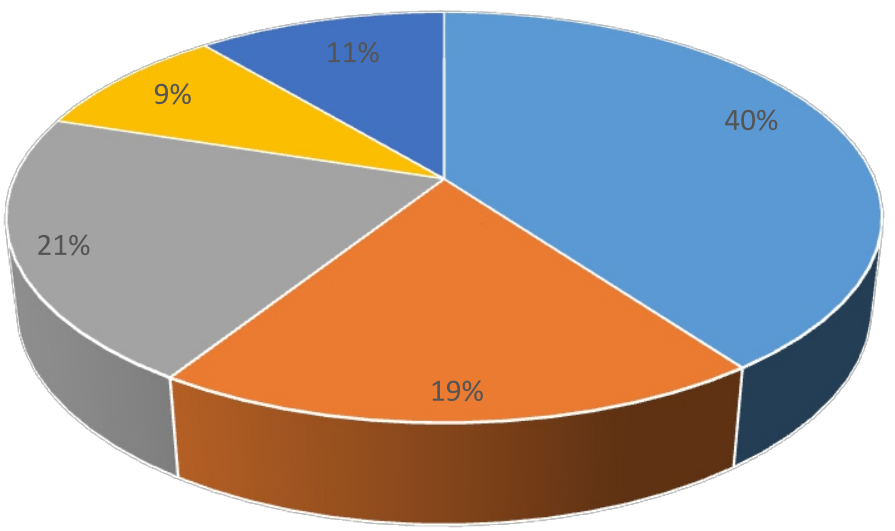

Section 3: Software and Online Literacy.

Graph 3.1: Microsoft Teams as Learning Platform.

Academic and Online Experiences: Online Assignment Submission and Login Experiences.

\section{Online assignment submission and login Experiences}

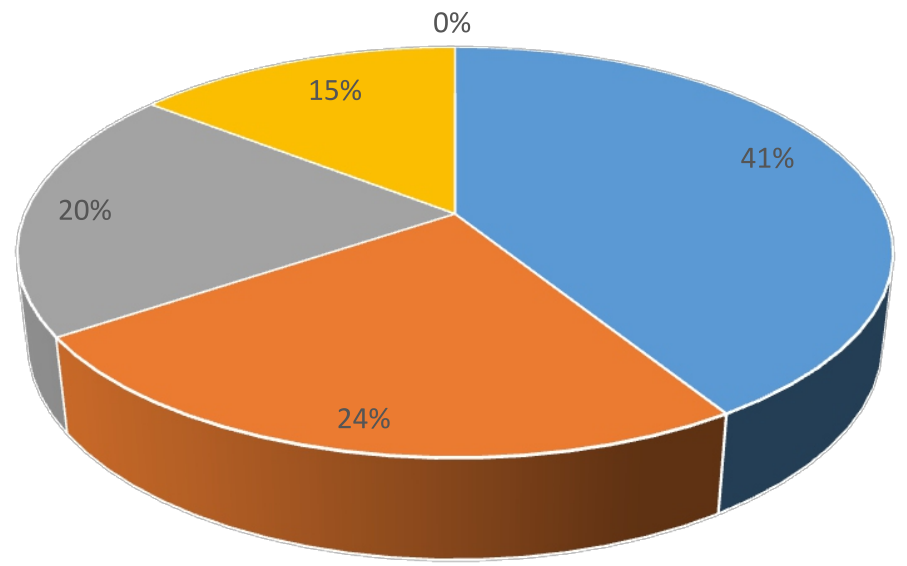

Graph 3.2: Online Assignment and Quizzes Submission. 
Difficulty Level for Students in Joining Microsoft Teams Meeting.

\section{Difficulty in joining Microsoft Teams Meeting}

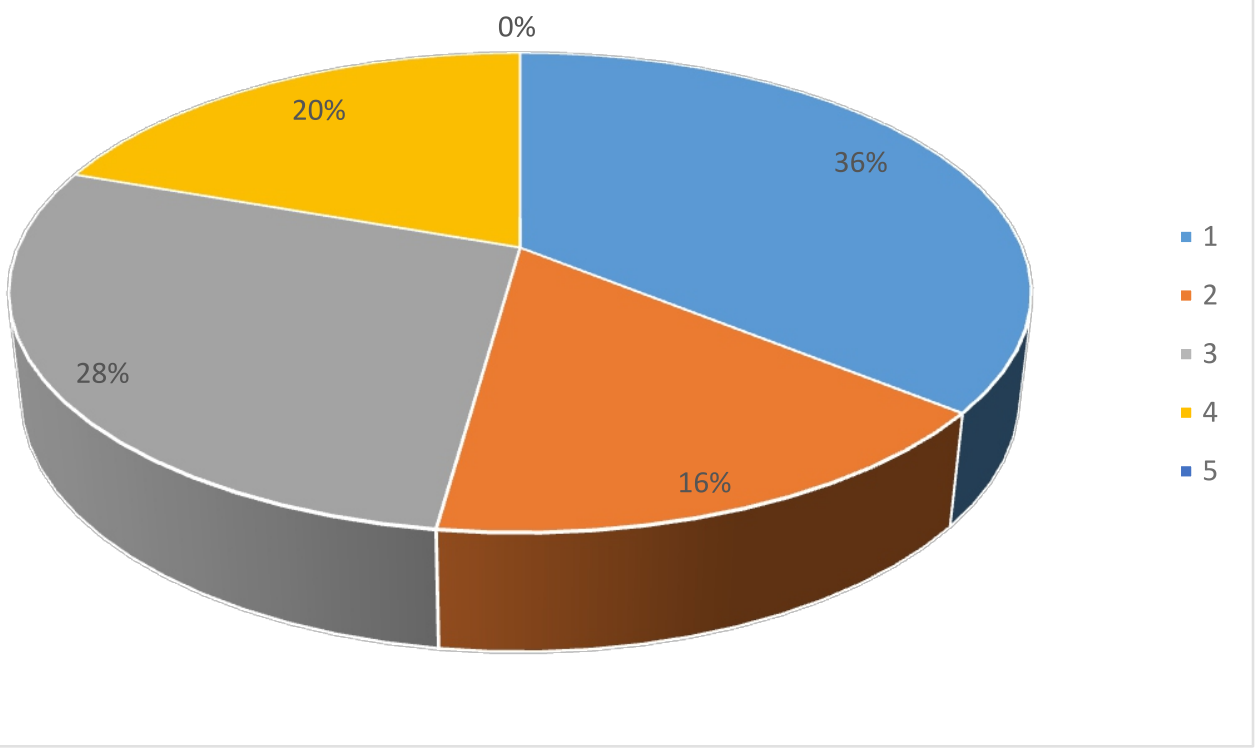

Graph 3.3: Difficulty Level for Students in Joining Microsoft Teams Meeting.

*KEY

- $\quad 1=$ easiest

- $\quad 5=$ most difficult

Section 4: Domestic and Social Issues:

This section was designed to get insight into student's issues from domestic backgrounds. What problem the students considered the greatest in learning from home. For that matter, some major issues were given in the form of closed-ended multiple-choice questions. Most of the students' considered poor internet quality the major issue in their online learning (as illustrated in graph 4.1: table 4/ annexes). Whereas lack of motivation for study at home was also a widely faced challenge in online learning. 
Domestic and Social Issues

Domestic and Social Issues

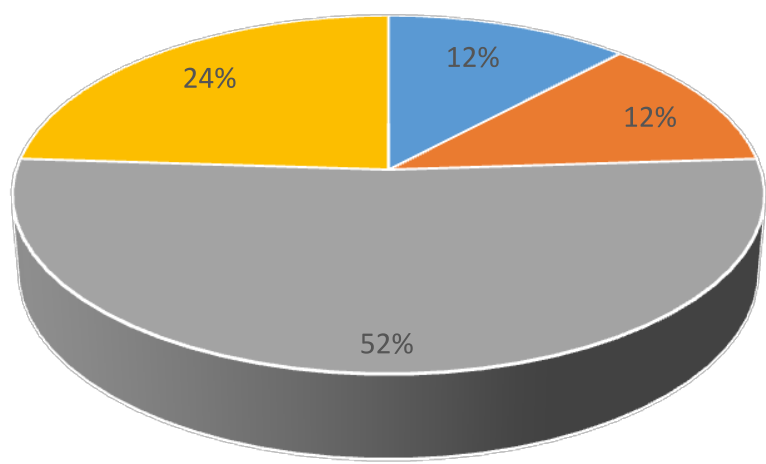

- Background Noises

- External Distractions

- Poor Internet Connections

- Lack of Motivation.

Section 4: Domestic and Social Issues

\section{Graph 4.1}

Section 5: Psychological Concerns:

Psychologically, this pandemic has affected the overall world population greatly and students are also affected by this shift in the learning system from on-campus classes to online learning. Some possible psychological concerns are tried to analyze in this study.

*KEY:

- $1=$ most

- $5=$ least 
Psychological Concerns: Anxiety over Online Classes. Anxiety over Online Classes

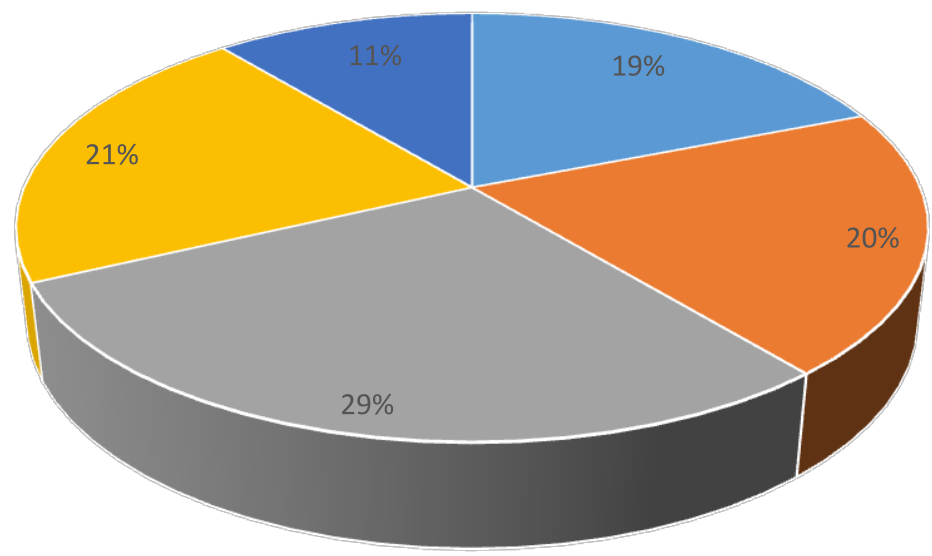

Section 5: Psychological Concerns.

Graph 5.1: Anxiety over Online Classes.

Psychological Concerns: Instructor's Support and Motivation.

\section{Instructor's Support and Motivation.}

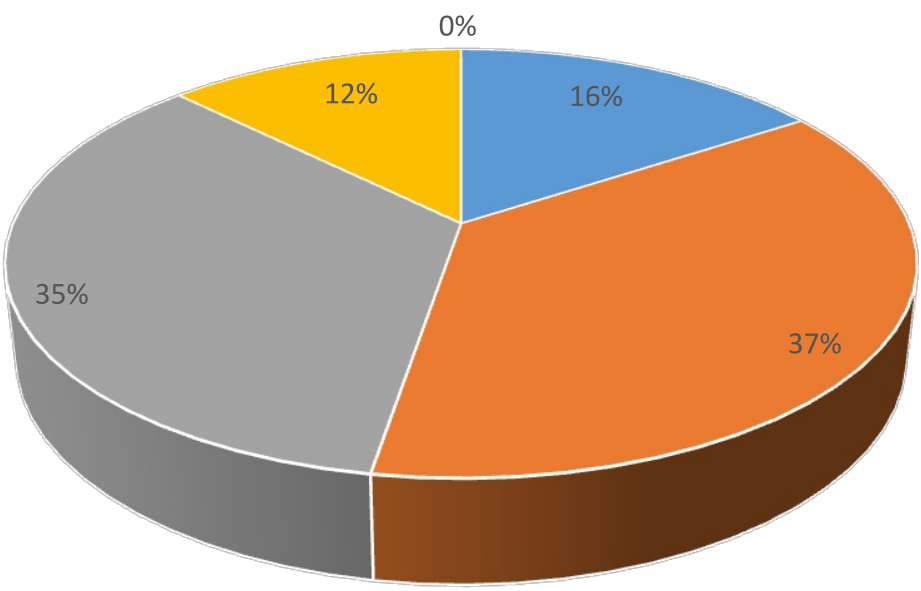

Section 5: Psychological Concerns.

Graph 5.2: Instructor's Support and Motivation. 
Online Learning for Shy Students.

\section{Online learning for Shy Students.}

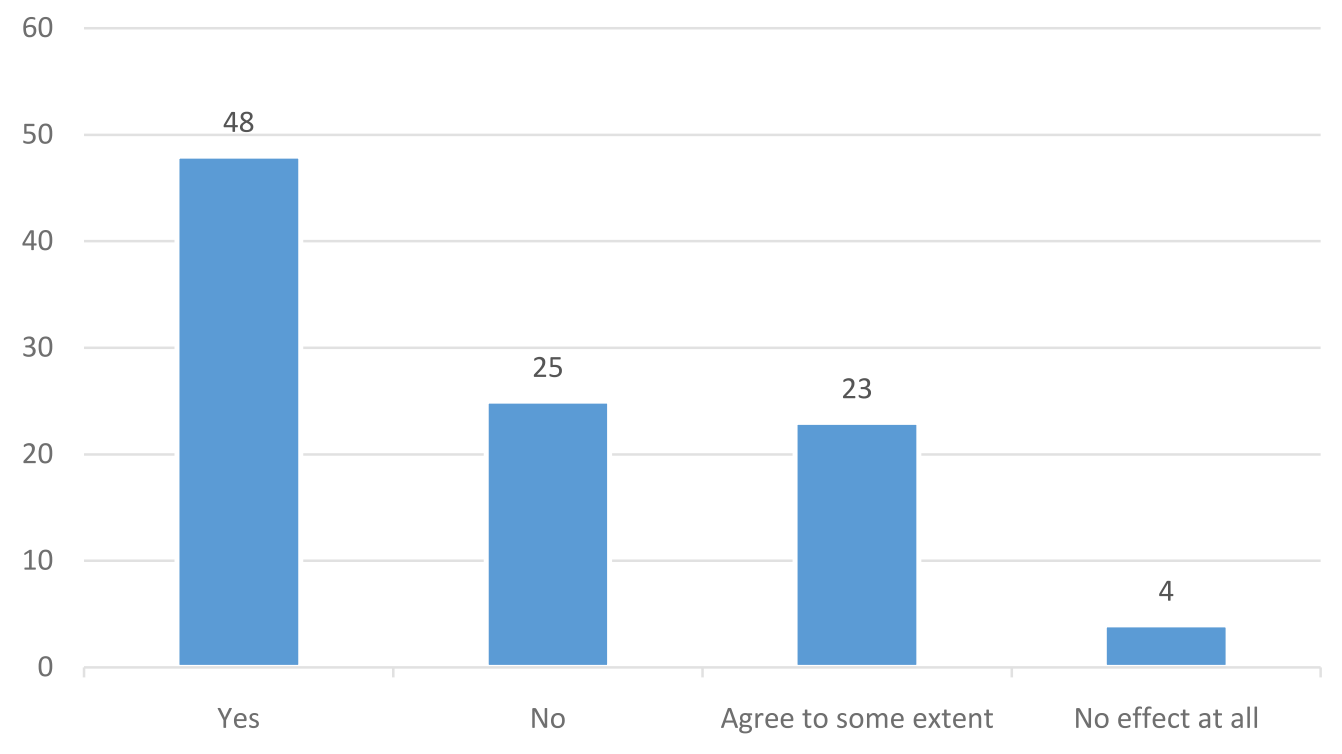

Section 5: Psychological Concerns.

Graph 5.3: Online Learning for Shy Students.

At the end of this closed-ended survey questionnaire, an open-ended question was included that was "online learning is good for shy people. Your opinion?" for this statement, the results (from graph 5.3: table 5.2/ annexes) show respondents' views on the effect of online classes on shy students. $48 \%$ of respondents had a view that online learning is good for shy people to participate and learn. While $25 \%$ of students had a contrary perspective that online classes had no good for shy students. $23 \%$ of students agreed to some extent whereas $4 \%$ students considered no reciprocal relation of online classes with introverted students.

\section{Discussion}

In this paper, we have observed learners' online learning experience and what challenges they have faced during the pandemic. COVID-19 disease was identified in Pakistan in March 2019. About 150 countries worldwide have introduced e-learning platforms as a solution to continue the education process during the pandemic. The survey targeted 100 participants 
and we have got 100 responses. $46 \%$ of them were male participants and 54\% of them were female. Candidates belong to several semesters. A diverse range of students belongs to the seventh/eighth semester. There is $5 \%$ of newcomers. The majority of the participants were undergraduate students. The results of this study revealed different levels of challenges. The major issue observed is a poor network connection and $52 \%$ of a pupil are concerned to this specific problem. In the second level, comes the lack of cooperation from students. $32 \%$ of them have neutral responses and $24 \%$ are dissatisfied as students do not bother to participate in lectures. Our data showed that MS Teams platform has been satisfactory for students in a pandemic. $37 \%$ of the population is satisfied with MS Teams and about 10\% felt difficulty. The result derived from data showed that $35 \%$ of the population was satisfied with instructors, satisfied with their cooperation and support but at the same time $33 \%$ of the participants fairly responded. A pupil has been anxious about e-learning. $20 \%$ of them were most anxious about distance learning, 11\% were least anxious and simultaneously $29 \%$ were even-handed in responding. Our data showed that MS Teams have been the easiest in using and $40 \%$ of the population have revealed this notion. We observed student's points of view by the result we have attained, the satisfaction of online learning. $36 \%$ of candidates gave neutral feedback. Results showed student's perception about attempting online quizzes and assignments, 25\% were happy, online assignments and quizzes appeared to be easiest yet $25 \%$ responses were neutral. It seems like half of the population is happy and satisfied but half of them are not satisfied with the current learning system.

\section{Conclusions}

The research work scrutinized the challenges and the students' experience in this Covid-19 pandemic about online learning. Covid-19 changed the procedure or way of learning throughout the world. The whole world is attempting to evade the gap and lessen the loss of students produced by the ongoing epidemic. An all-inclusive, online education environment authorized learning to take place in such a setting that's not limited by time or place. Online education has the potential to dissimulate hurdles that generally have been erected by disability, poverty, and location, together with other factors. 
Nevertheless, the consequences of online learning are not every time a blessing or favour to the student's community, several obstacles and problems were faced by the students during this whole scenario of online education. The research focused to estimate or evaluate the perspective of undergraduate students in consonance with online learning. This research study is formed on a large population, which was studying at the University of Central Punjab, under different faculty using the mixed-method design. We adapted the questionnaire and it was conducted on Google forms, and the survey was performed by 100 students studying in different departments of UCP. We have got 100 responses. $46 \%$ of them were male participants and the rest $54 \%$ of them were female. We can distinctly observe a student's perspective and viewpoint by the result we have attained, the contentment of online learning. $36 \%$ of candidates gave neutral feedback. Results showed student's perception about attempting online quizzes and assignments, 25\% were happy, online assignments and quizzes appeared to be easiest yet $25 \%$ responses were neutral. It seems like half of the population is content and self-satisfied but half of them is not pleased with the current learning system.

\section{References:}

Akkoyunlu, B., \&Soylu, M. Y. (2008). A study of student's perceptions in a blended learning environment based on different learning styles. Journal of Educational Technology \& Society, 11(1), 183-193.

Allen, I. E., \& Seaman, J. (2014). Grade Change: Tracking Online Education in the United States. Babson Survey Research Group.

Almaiah, M. A., Al-Khasawneh, A., \&Althunibat, A. (2020). Exploring the critical challenges and factors influencing the E-learning system usage during COVID19 pandemic. Education and Information Technologies, 25, 5261-5280.

Beldarrain, Y. (2006). Distance education trends: Integrating new technologies to foster student interaction and collaboration. Distance education, 27(2), 139-153.

Chang, C. S., Liu, E. Z. F., Sung, H. Y., 
Lin, C. H., Chen, N. S., \& Cheng, S. S. (2014). Effects of online college student's Internet self-efficacy on learning motivation and performance. Innovations in education and teaching international, 51(4), 366-377.

Chattopadhyay, S., De, U. K., Saha, B., Kumar, A., Ramachandran, M., Mohanan, P. C., ... \& Das, D. ( $\left.\begin{array}{llll}2 & 0 & 2 & 0\end{array}\right)$. Journal of Development Policy Review (JDPR): Vol. 1 Issues. 1 and 2 (2020): Special Issue-The COVID-19 Pandemic and India. IndraStra Global eJournal Hosting Services.

Chen, C. C., \& Jones, K. T. (2007). Blended learning vs. traditional classroom settings: Assessing the effectiveness and student perceptions in an MBA accounting course. Journal of educators online, 4(1), n1.

Davies, J., \& Graff, M. (2005). Performance in e-learning: online participation and student grades. British Journal of Educational Technology, 36(4), 657-663.
Doo, M. Y. (2006). A problem in online interpersonal skills training: do learners practice skills?. Open Learning: The Journal of Open, Distance and e-Learning, 21(3), 263-272.

Dziuban, C. D., Moskal, P., \& Hartman, J. (2005). Higher education, blended learning, and the generations: Knowledge is power-No more. Needham, MA: Sloan Center for Online Education, 88-89.

Faidley, J. (2018). Comparison of learning outcomes from online and face-to-face accounting courses.Electronic Theses and Dissertations. Paper 3434. https://dc.etsu.edu/etd/3434

Fry, K. (2001). E-learning markets and providers: some issues and prospects. Education+ Training.

Hannay, M., \&Newvine, T. (2006). Perceptions of distance learning: A comparison of online and traditional learning. Journal of online learning and teaching, 2(1), 1-11.

Jaques, D., \& Salmon, G. (2007). Learning in groups: A 
handbook for face-to-face and online environments. Routledge.

Jeong, H. C., \& So, W. Y. (2020). Difficulties of online physical education classes in middle and high school and an efficient operation plan to address them. International journal of environmental research and public health, 17(19), 72-79.

Singh, V., \& Thurman, A. (2019). How many ways can we define online learning? A systematic literature review of definitions of online learning (1988-2018). American Journal of Distance Education, 33(4), 289-306. 


\section{Annexes:}

Frequency Distribution of Section 1: Demographics

\begin{tabular}{|c|c|c|}
\hline Gender & Frequency & Percentage \\
\hline Female & 54 & $54 \%$ \\
\hline Male & 46 & $46 \%$ \\
\hline Total & 100 & $100 \%$ \\
\hline Current Semester & & \\
\hline 1,2 & 5 & $5 \%$ \\
\hline 3,4 & 10 & $10 \%$ \\
\hline 5,6 & 13 & $13 \%$ \\
\hline 7,8 & 72 & $72 \%$ \\
\hline & & \\
\hline Department & 46 & $46 \%$ \\
\hline $\begin{array}{c}\text { Faculty of Arts and } \\
\text { Social Sciences. }\end{array}$ & 20 & $20 \%$ \\
\hline UCP Business School. & 4 & $4 \%$ \\
\hline $\begin{array}{c}\text { School of Accounting } \\
\text { and Finance. }\end{array}$ & 6 & $6 \%$ \\
\hline $\begin{array}{c}\text { School of Media and } \\
\text { Communication Studies. }\end{array}$ & 24 & $24 \%$ \\
\hline UCP Law School. & & \\
\hline
\end{tabular}

Section1: Table 1

Frequency Distribution of Section 2: Academic Experiences

\begin{tabular}{|c|c|c|c|c|c|}
\hline Question & $\mathbf{1}$ & $\mathbf{2}$ & $\mathbf{3}$ & $\mathbf{4}$ & $\mathbf{5}$ \\
\hline Effectiveness of e-learning & 15 & 19 & 38 & 15 & 13 \\
\hline Satisfaction with online learning & & & & & \\
\hline Student's class response rate & 11 & 19 & 36 & 20 & 14 \\
\hline & 7 & 18 & 32 & 24 & 19 \\
\hline Satisfaction with online grading & & & & & \\
\hline & 20 & 26 & 24 & 16 & 14 \\
\hline Experience in online quizzes \& assignments. & 25 & 24 & 25 & 16 & 10 \\
\hline
\end{tabular}

Section 2: Table2

- $1=$ strongly satisfied

- $5=$ strongly dissatisfied 
Frequency distribution of section 3: Online Literacy and Software

\begin{tabular}{|c|c|c|c|c|c|}
\hline Question & $\mathbf{1}$ & $\mathbf{2}$ & $\mathbf{3}$ & $\mathbf{4}$ & $\mathbf{5}$ \\
\hline $\begin{array}{c}\text { Microsoft Teams as a learning } \\
\text { platform }\end{array}$ & 40 & 19 & 21 & 09 & 11 \\
\hline $\begin{array}{c}\text { Online assignment submission and } \\
\text { login experiences }\end{array}$ & 37 & 22 & 18 & 13 & 10 \\
\hline $\begin{array}{c}\text { Difficulty in joining Microsoft Teams } \\
\text { meeting }\end{array}$ & 33 & 15 & 26 & 18 & 08 \\
\hline & & & & & \\
\hline
\end{tabular}

Section 3: Table 3

- $1=$ easiest

- $5=$ most difficult

Frequency distribution of section 4: Domestic and Social Issues.

\begin{tabular}{|c|c|c|}
\hline Issues & Frequency & Percentage \\
\hline Background Noises. & 12 & $12 \%$ \\
\hline External Distractions. & 12 & $12 \%$ \\
\hline $\begin{array}{c}\text { Poor Internet } \\
\text { Connections. }\end{array}$ & 52 & $52 \%$ \\
\hline $\begin{array}{c}\text { Lack of Motivation for } \\
\text { Study. }\end{array}$ & 24 & $24 \%$ \\
\hline
\end{tabular}

Section 4: Table 4

Frequency distribution for Section 5: Psychological Concerns

\begin{tabular}{|c|c|c|c|c|c|}
\hline Questions & $\mathbf{1}$ & $\mathbf{2}$ & $\mathbf{3}$ & $\mathbf{4}$ & $\mathbf{5}$ \\
\hline Anxiety over online classes & 19 & 20 & 29 & 21 & 11 \\
\hline $\begin{array}{c}\text { Instructor's Support and } \\
\text { Motivation }\end{array}$ & 15 & 35 & 33 & 12 & 05 \\
\hline & & & & & \\
\hline
\end{tabular}

Section 5: Table 5.1

- $1=$ most

- $5=$ least 
Responses to open-ended questions are given as:

\begin{tabular}{|c|c|c|c|}
\hline Question: & Frequency: & Percentage: & Coding \\
\hline $\begin{array}{c}\text { Online learning is } \\
\text { good for shy } \\
\text { people? }\end{array}$ & 48 & $48 \%$ & $\mathrm{~A}$ \\
\hline Yes & 25 & $25 \%$ & $\mathrm{~B}$ \\
\hline No & 23 & $23 \%$ & $\mathrm{C}$ \\
\hline $\begin{array}{c}\text { Agree to some } \\
\text { extent }\end{array}$ & 04 & $04 \%$ & $\mathrm{D}$ \\
\hline No effect at all. & & & \\
\hline
\end{tabular}

Section 5: Table 5.2

\section{Appendices:}

https://forms.gle/KXaEnj2ZwpEhymuY9 